\title{
LEAF AREA AND PASTURE GROWTH
}

\begin{abstract}
GRICULTURISTS are ultimately concerned with yield per unit area of land, and it is the aim of plant physiologists interested in agricultural problems to attempt to analyse the causes of variation in yield. In a recent review entitled "The Significance of Leaf Area in Pasture Growth", by C. M. Donald and J. N. Black of the Waite Agricultural Research Institute, Australia (Herbage Abstracts, $28 ; 1958$ ), it is pointed out that of the chief physical factors limiting yield, water and nutrients have received more attention than light, particularly in pasture studies. Under field conditions the amount of light falling on a pasture is not controlled by man, nor is it subject in any particular locality to the same degree of annual fluctuation as is rainfall. When light is the only limiting factor the ultimate capacity of a species to produce dry matter depends on the degree to which a community of such plants can exploit the light falling on it. This will depend on the habit of the plant. The yield, therefore, will depend to a great extent on the area of photosynthetic tissue which is able to intercept light energy, that is, the leaf area. Consequently, the important factor is the relationships of leaf surface to soil surface, and this was first put on a quantitative basis by D. J. Watson in his concept of 'leaf area index', which is defined as the leaf area per unit area of land. This index has the virtue of being a measure of the whole crop rather than of individual plants.

Watson postulated that the greatest dry-matter production would occur when the maximum leaf area coincided with seasonal conditions most favourable for photosynthesis. The development of a leaf system capable of intercepting a high proportion
\end{abstract}

of the incoming light energy is of great importance in the growth of field crops; at values of the index below this level, maximum growth cannot occur. On the other hand, at higher values mutual shading of leaves may result in a reduction in growth-rate of the crop.

The limited number of determinations of the leaf area index of pastures suggests that these values may considerably exceed that of crops, and it is suggested that there may be several reasons for this. First of all, the types of plants which have been selected by man to sow pastures for his animals are those with heavy leaf production. A second major aspect affecting the index is the greater number of plants per unit area in pastures compared with crops.

The authors emphasize that the application of the concept of leaf area index to problems of pasture growth is of great potential value. They stress that provided other conditions are optimum light is the only limiting factor determining productivity of a pasture and that efforts to increase production beyond the high levels. already recorded in some environments may be in vain unless this limiting factor is fully appreciated. With these concepts clearly in mind the object in pasture management will be to pass as rapidly as possible to the optimum leaf area index for pasture growth and then to hold the pasture at this level. Any operations which delay this process, such as early grazing when the index is low, will substantially delay attainment of the optimum and may have an effect on subsequent production quite disproportionate to the amount removed. Other aspects of pasture production capable of analysis in terms of leaf area index are pointed out.

\section{LABORATORIES IN GRAMMAR SCHOOLS}

T HE inadequate provisions for science teaching in grammar schools have been brought out only too clearly in the answers to a questionnaire which was sent to some 2,000 schools about a year ago*. The 472 schools from which data were considered are widely distributed over the whole of England and Wales, with a slight bias towards London and the surrounding counties.

These schools contained about 25,000 pupils, of whom 90.9 per cent took some science. This is a reassuringly high proportion which does not vary much between the extremes of 86.5 per cent in independent boys' schools and $\mathbf{9 3 . 9}$ per cent in the small grammar schools. How much science was studied was not indicated, and, for many pupils, the time devoted to science may be very small, perhaps only one or two periods a week.

Almost all pupils do some science in the first three years of their secondary courses. In the fourth year the percentage figures drop a little, and in the fifth (O-level) year, about 90 per cent of pupils are taking science, although not all of these will offer science subjects in the O-level examination. The dropping of science in the fourth and fifth years may occur

* School Science Review, 39, No. 139; June 1958. because subject specialization is already starting, or it may be because sufficient teachers or laboratories or both are not available.

In the sixth form there is a considerable fall in the percentage of pupils taking some science. This is particularly marked in the girls' schools, being only 47 per cent in the two categories of grammar schools having 300-399 pupils and 400-549 pupils, 44 per cent in the 500-699 category, and 39 per cent in the larger schools. The corresponding figures for boys' schools are $66,60,61$ and 65 per cent.

Expressed as a percentage of total sixth-form numbers, the figures for girls' schools are about half of those for boys' schools. Since the sixth forms in girls' schools are smaller than in boys' schools, the number of girls specializing in science is less than half the number of boys.

These results support the view that girls' schools could be an important source of the increased number of scientists required in industry, in Government departments, for teaching and for many other purposes.

One question required each school to state its total number of laboratories and other rooms having a special connexion with the teaching of science. Using 
the standards framed by other responsible bodies, namely, the Ministry of Education and the Committee of the Industrial Fund for the Advancement of Scientific Education in Schools, the figures reveal the inadequacy of existing provisions.

More than half of the schools which appear to be adequately provided with laboratories by Ministry of Education standards are girls' and mixed schools which, if considered by the higher standards the Ministry adopts for boys' schools, would not be regarded as adequately provided.

An attempt was also made to discuss the existing provision for laboratory assistance. Out of 362 maintained grammar schools answering the questionnaire, 92 (25 per cent) have no laboratory assistance at all. $31(8.6$ per cent) have only part-time help, and 78 (22 per cent) have only one junior assistant. 85 per cent are not adequately provided with laboratory assistance.

The amount spent each year on science in grammar schools is revealing. 144 out of 337 maintained grammar schools, that is, 43 per cent, had less than $8 s$. per year per pupil taking science. At one extreme an independent boys' school has $£ 310 s$. per year for each pupil taking science, while one direct-grant boys' school has $£ 2$, and one independent girls' school has $£ 115 s .9 d$. The highest figure shown by a maintained boys' school is $£ 18 s$. $8 d$., and for girls' $£ 15 s .10 d$. At the other extreme, one boys' grammar school has only between $1 s .3 d$ and $3 s .6 d$. annually for each pupil taking science. Financially, as in other respects, girls' schools are, in general, considerably worse off than boys' schools. It appears that the schools with less than $10 s$. yearly for each pupil taking science (that is, about half of the grammar schools) are being subjected to conditions which are frustrating and inimical to the work they are called upon to do.

Schools were invited to make general comments concerning difficulties encountered in science departments. 256 schools gave seventy different reasons for the difficulties they faced. Among reasons given which received considerable support were : $(a)$ accommodation generally cramped and crowded (79); (b) sharing accommodation or using another school's science laboratories (13); (c) laboratories too small (14); (d) no advanced laboratories $(16)$; (e) laboratories widely dispersed-in several cases by a mile or more $(19)$; $(f)$ no preparation rooms $(10)$; $(g)$ outof-date and/or ill-designed laboratories (14); $(h)$ laboratories used as form rooms (21); (i) much science teaching in class-rooms $(16) ;(j)$ serious shortage of storage space $(22) ;(k)$ inadequate finance, lack of capital grant, etc. $(33) ;(l)$ shortage of staff $(28) ;(m)$ lack of suitable qualified staff $(28)$; (n) too many young and inexperienced staff (14); (o) staffing ration not generous enough, time-table too heavy, etc. $(17) ;(p)$ classes far too large (24); $(q)$ no laboratory assistants $(22)$; $(r)$ inadequate or poor quality laboratory assistants (48).

\section{MEDICAL RESEARCH IN INDIA}

$\mathrm{T}$ HE Technical Report of the Scientific Advisory Board, published annually by the Indian Council of Medical Research (pp. xii +290. New Delhi : Indian Council of Medical Research, 1957. Rs. 1), has primarily included detailed reports of work done under all the research schemes financed by the Council during the year. The report for 1956, as a measure of economy, contains only short abstracts of work done under research schemes financed during 1955-56. Of these, 52 relate to chemical research, 5 each to cholera and leprosy, 9 to malaria and other arthropod-borne diseases, 10 to tuberculosis, 3 to venereal disuases, 4 each to environmental hygiene and sanitation and to industrial health, 16 each to maternal and child health, to nutrition, to physiology and pharmacology, 1 to mental health, and 7 to virus diseases. Besides details of the Scientific Advisory Board and its Advisory Committees and Sub-committees, the report includes lists of papers published by workers of the Indian Council of Medical Research in 1956 and of those dealing with work done under the auspices of the Council and published in 1956.

From this array of papers it is almost impossiblo to select any for particular mention, but as of more general scientific interest reference may be made to the electron microscopic investigations on microorganisms under Prof. K. N. Das Gupta at the Institute of Nuclear Physics, Calcutta; to the leprosy research work under Dr. N. Mukerjee at the School of Tropical Medicine, Calcutta ; the laboratory and fiold investigations at the Malaria Institute of India, Delhi, on resistance in houseflies and mosquitoes to chlorinated hydrocarbon insecticides and the comparative efficiency of different insecticides against mosquitoes; on the control of $W$. malayi filariasis in Travancore-Cochin with diethylcarb. amazine; the studies in vitamins, proteins and fats at the Nutrition Research Laboratories, Coonoor; and on the biosynthesis of ascorbic acid by the Nutrition Research Unit at the University College of Science and Technology, Calcutta.

The Indian Council of Medical Research has also issued a review of the progress made in the research projects it sponsors covering the whole of the period 1950-57 (pp. v + 169. New Delhi : Indian Council of Medical Research, 1957). The survey is intended to convey some idea of the philosophy and approach of the Indian Council of Medical Research to the development of medical research in India, the contribution being made towards public health and the direction in which it is moving. Among the features stressed in the introductory review are the measures taken against malaria, filariasis, leprosy, plague, tuberculosis, trachoma and preventable blindness; the new outlook on cholera and venereal disease and malnutrition and virus disease. The survey gives a concise and readable account of the organization of medical research in India, both in diverse fields of research, between different institutions and of the balance between fundamental and applied research. Besides this section, which displays a vision, determination and resource on which the Council and Government of India are to be highly congratulated, there is a section on progress in selected fields, while a further section on the year ahead, as well as the concluding section, show that the Council is fully alive to the factors upon which effective scientific work depends and is seeking to provide the scientist, not simply with the institutions and equipment, but also with the conditions of service in which he can give of his best. 